\title{
Corrigendum: Potent Restriction of Sexual Zika Virus Infection by the Lipid Fraction of Extracellular Vesicles in Semen
}

\author{
Ruofan Wang ${ }^{1}$, Germán G. Gornalusse ${ }^{1}$, Yeseul Kim ${ }^{1}$, Urvashi Pandey ${ }^{1}$, Florian Hladik ${ }^{1,2,3}$ \\ and Lucia Vojtech ${ }^{1 *}$
}

${ }^{1}$ Department of Obstetrics and Gynecology, University of Washington, Seattle, WA, United States, ${ }^{2}$ Division of Allergy and Infectious Diseases, Department of Medicine, University of Washington, Seattle, WA, United States, ${ }^{3}$ Vaccine and Infectious Disease Division, Fred Hutchinson Cancer Research Center, Seattle, WA, United States

Keywords: Zika virus, flavivirus, semen, extracellular vesicles, exosomes, female, genital, vagina

\section{A Corrigendum on}

Potent Restriction of Sexual Zika Virus Infection by the Lipid Fraction of Extracellular Vesicles in Semen

\section{OPEN ACCESS}

Edited and reviewed by: Lisa Sedger,

University of Technology

Sydney, Australia

${ }^{*}$ Correspondence: Lucia Vojtech luciav@uw.edu

Specialty section: This article was submitted to Virology,

a section of the journal

Frontiers in Microbiology

Received: 10 May 2021 Accepted: 19 May 2021

Published: 15 June 2021

Citation:

Wang R, Gornalusse GG, Kim Y, Pandey U, Hladik F and Vojtech L

(2021) Corrigendum: Potent Restriction of Sexual Zika Virus Infection by the Lipid Fraction of Extracellular Vesicles in Semen.

Front. Microbiol. 12:707875. doi: 10.3389/fmicb.2021.707875 by Wang, R., Gornalusse, G. G., Kim, Y., Pandey, U., Hladik, F., and Vojtech, L. (2020). Front. Microbiol. 11:574054. doi: 10.3389/fmicb.2020.574054

In the original article, there was a mistake in the legend for Figure 4 as published. Figure 4E depicts the effect of pre-incubating liposomes with either ZIKV or cells, but the legend mistakenly says SEV rather than liposomes. The correct legend appears below.

Figure 4. Lipid content of SEV blocks ZIKV infection. (A) The protein content of SEV was denatured by heating at $95^{\circ}$ for $8 \mathrm{~min}$. Nanoparticle tracking analysis (NTA) profile comparing heat-treated and untreated SEV showing that the size profiles do not change. Size profiles of liposomes (see part C) are also plotted. (B) Equal amounts of heat-treated or untreated SEV were incubated with ZIKV virions at a $10^{6} \mathrm{SEV}: \mathrm{PFU}$, then added to epithelial cell lines for $1.5 \mathrm{~h}$ before washing and assessing ZIKV binding by ddPCR. As a control, ZIKV virions were also heated at $95^{\circ}$ for $8 \mathrm{~min}$. Each line is a separate cell line, points are mean of two replicate wells and error bars are standard deviation. Significance by one-way ANOVA with Tukey's multiple comparisons test. ${ }^{* *} p$ $>0.01$. (C) ZIKV was pre-incubated with $10^{6} \mathrm{SEV}$ or $10^{6}$ liposomes for $1 \mathrm{~h}$ prior to infecting genital epithelial cells. Seventy-two hours post-infection cells were lysed and ZIKV genomes quantified by ddPCR. Each line is the average of duplicate wells from a separate experiment. Reduction in ZIKV genomes was significant by one-way ANOVA with Dunnett's multiple comparisons test. * $p<0.05$, and ${ }^{* *} p<0.005$. (D) The data from $\mathbf{C}$, and additional conditions with $10^{5} \mathrm{SEV}$ or liposomes, are plotted as percent reduction from ZIKV alone. Each symbol represents the average of two technical wells from a different cell line. The horizontal lines are the mean for each condition. (E) Comparison of pre-incubation of either ZIKV or epithelial cells with liposomes on viral infection. Liposomes were pre-incubated with ZIKV (ratio: $10^{6}$ liposome per PFU) or with cells (same amount of liposomes) for $1 \mathrm{~h}$ at $37^{\circ}$, then virus was added to cells for $1.5 \mathrm{~h}$. Cells were washed and cell-associated ZIKV genomes quantified by ddPCR. Each symbol represents the average of 
two technical replicates from different epithelial cell lines. Significance by one-way ANOVA with Dunnett's multiple comparisons test. ${ }^{*} p<0.05$.

The authors apologize for this error and state that this does not change the scientific conclusions of the article in any way. The original article has been updated.
Copyright (๑) 2021 Wang, Gornalusse, Kim, Pandey, Hladik and Vojtech. This is an open-access article distributed under the terms of the Creative Commons Attribution License (CC BY). The use, distribution or reproduction in other forums is permitted, provided the original author(s) and the copyright owner(s) are credited and that the original publication in this journal is cited, in accordance with accepted academic practice. No use, distribution or reproduction is permitted which does not comply with these terms. 